\title{
Produção de conhecimento sobre políticas para formação e carreira docentes no Brasil
}

\author{
Knowledge production on policies for teachers' formation and career in Brazil \\ Producción de conocimiento sobre políticas de formación y carrera docentes \\ en Brasil
}

\section{ISABEL MELERO BELLO \\ MARIETA GOUVÊA DE OLIVEIRA PENNA \\ MIRNA RIBEIRO LIMA DA SILVA}

Resumo: $\mathrm{O}$ artigo analisa a produção acadêmica sobre políticas para a formação e carreira docentes em resumos de teses e dissertações da área de educação defendidas no período 20002010 no Brasil. O mapeamento permitiu caracterizar esses trabalhos quanto ao ano de defesa, nível do curso, orientadores, linhas de pesquisa, tópicos pesquisados, referenciais teóricos utilizados e instituições de origem, permitindo compreender como está se configurando o campo. Considera-se que houve ampliação de estudos sobre o tema no período, mas também dispersão dos trabalhos entre diferentes Linhas de Pesquisa e orientadores.

Palavras-chave: Formação e carreira docentes; pesquisa em educação; campo educacional.

Abstract: This paper analyzes the academic production about policies for teacher career and training in abstracts of dissertations and thesis in the education between 2000 and 2010 in Brazil. The mapping allowed us to characterize these works by date of defense, level, advisors and research lines, themes of research, theoretical references and home institutions, allowing us to understand how the field is shaping. We consider that there has been an increase of studies on the subject in that period, but also a certain dispersion of the works between different research lines and advisors.

Keywords: Teacher career and training; educational research; educational field.

Resumen: El artículo analiza la producción académica sobre políticas para la formación y carrera docentes en resúmenes de tesis y disertaciones del área de educación defendidas entre 2000 y 2010 en Brasil. El mapeo permitió caracterizar esos trabajos según el año de defensa, nivel del curso, orientadores, líneas de investigación, tópicos investigados, referenciales teóricos utilizados e instituciones de origen, permitiendo comprender como se está configurando el campo. Se considera que hubo un aumento en los estudios sobre el tema en el período investigado, pero también que hubo dispersión entre diferentes líneas de investigación y orientadores.

Palabras clave: Formación y carrera docentes; investigación en educación; campo educacional. 


\section{INTRODUÇÃO}

O objetivo deste artigo é apresentar parte de dados e resultados de um estudo interinstitucional, financiado pela Coordenação de Aperfeiçoamento de Pessoal de Nível Superior (Capes) e pelo Conselho Nacional de Desenvolvimento Científico e Tecnológico (CNPq). Particularmente, objetiva-se analisar as tendências de pesquisa no Brasil com foco em políticas de formação de professores e na carreira docente, a fim de traçar esforço na compreensão da constituição do campo educacional na atualidade. De acordo com Bourdieu (2003, 2004), o conceito de campo diz respeito ao espaço de posições disputadas por agentes em torno de interesses específicos, relacionados à produção, reprodução e distribuição dos capitais em jogo no espaço em questão. Para análise das formas de constituição de determinado campo, faz-se necessário o estabelecimento de análises que evidenciem mecanismos internos próprios ao campo e suas formas de organização, bem como externos, vinculados à sociedade mais ampla.

Trata-se de recorte feito a partir de pesquisa mais abrangente, sobre a produção discente em políticas educacionais, que contou com equipe composta por docentes e estudantes provenientes de seis instituições públicas de ensino superior, situadas em cinco estados do país. O objetivo do grupo é analisar a produção do conhecimento em política educacional em programas de pósgraduação em educação.

A produção de conhecimento está sendo compreendida a partir de Tello (2013a, p. 764), ou seja, aquela que se dá com o recorte de um objeto de estudo, seleção de metodologia para a busca de informações e mobilização de conceitos para sua análise. De acordo com Tello (2012, 2013b) ou, mesmo, Mainardes (2009), a área enfrenta problemas em sua produção acadêmica, explicitando falta de precisão teórica e metodológica. Nesse sentido, defende-se aqui a ideia de que, no atual estágio, é fundamental a realização de estudos sobre as principais características da produção acadêmica em educação do Brasil.

O corpus de análise refere-se às teses e dissertações produzidas no período de 2000 a 2010 no âmbito de programas de pós-graduação em educação cuja nota de avaliação da Capes foi igual ou superior a cinco no triênio 2008-2010. Os programas selecionados estão nas seguintes instituições de ensino: PUC-RJ, UERJ, UFMG, PUC-RS, UFF, Unisinos, USP, PUC-SP, UFES, UFG, UFPel, UFPR, UFRGS, UFRJ, UFRN, UFSCar, UFU, Unesp-Marília, Unicamp e Unimep.

Para tanto, em 2012, realizou-se a coleta dos dados no Banco de Teses da Capes, no âmbito de cada programa de pós-graduação adequado ao critério de avaliação estabelecido. Inicialmente tentou-se realizar a busca dos trabalhos diretamente dos Repositórios Institucionais das instituições; encontraram-se, 
porém, formas de organização muito divergentes dessas bases. Isso levou a se eleger como base única de levantamento e análise de dados o Banco de Teses e Dissertações da Capes. Foram levantados 1.283 trabalhos, com base nos eixos relacionados no Quadro 1.

\section{Quadro 1: Eixos temáticos e palavras utilizadas na coleta}

\begin{tabular}{|c|c|}
\hline Eixo temático & Palavras utilizadas na coleta dos trabalhos \\
\hline $\begin{array}{l}1 \text { - Organização, planejamento, administração e } \\
\text { gestão da educação }\end{array}$ & $\begin{array}{c}\text { planejamento; organização da educação; planejamento } \\
\text { educacional; administração }\end{array}$ \\
\hline $\begin{array}{c}2 \text { - Avaliação em larga escala e avaliação } \\
\text { institucional }\end{array}$ & $\begin{array}{c}\text { avaliação educacional; avaliação da educação; } \\
\text { avaliação na educação; avaliação em educação; } \\
\text { avaliação externa; avaliação institucional; avaliação } \\
\text { em larga escala; avaliação de larga escala; exame } \\
\text { nacional; Saeb; Prova Brasil; Provinha Brasil }\end{array}$ \\
\hline 3 - Qualidade da educação e do ensino & qualidade da educação; qualidade de ensino \\
\hline $\begin{array}{c}4 \text { - Estado e reformas educacionais, neoliberalismo } \\
\text { na educação, terceiro setor e organizações sociais } \\
\text { na educação, análise e avaliação de políticas } \\
\text { educacionais }\end{array}$ & $\begin{array}{l}\text { Estado; reformas educacionais; reforma do Estado; } \\
\text { neoliberalismo na educação }\end{array}$ \\
\hline $\begin{array}{l}5 \text { - Políticas de formação de professor e carreira } \\
\text { docente }\end{array}$ & $\begin{array}{c}\text { formação de professor; formação docente; licenciatura; } \\
\text { trabalho docente; profissionalização docente; carreira } \\
\text { docente; magistério; remuneração docente; piso salarial } \\
\text { do magistério; salário do professor }\end{array}$ \\
\hline $\begin{array}{c}6 \text { - Financiamento da educação e controle social do } \\
\text { financiamento da educação }\end{array}$ & $\begin{array}{l}\text { financiamento; controle social; gasto público e } \\
\text { educação; Fundef; Fundeb; recursos públicos; } \\
\text { Conselho de Acompanhamento; Controle Social do } \\
\text { Fundeb; Conselho de Acompanhamento do Fundef }\end{array}$ \\
\hline $\begin{array}{l}7 \text { - Abordagens teórico metodológicas em } \\
\text { pesquisas sobre políticas educacionais }\end{array}$ & $\begin{array}{l}\text { abordagens teórico-metodológicas; pesquisa; políticas } \\
\text { públicas; políticas educacionais; educação; produção } \\
\text { em políticas educacionais; programas de educação }\end{array}$ \\
\hline $\begin{array}{c}8 \text { - Análise e avaliação de programas e projetos no } \\
\text { campo educacional }\end{array}$ & $\begin{array}{c}\text { educação permanente; educação superior; ensino } \\
\text { superior }\end{array}$ \\
\hline 9 - Políticas inclusivas & programas; assistência ao estudante \\
\hline
\end{tabular}

Fonte: Banco de dados da pesquisa.

As categorias expostas no Quadro 1 foram consolidadas após amplo processo de análise dos resumos de um primeiro lote de trabalhos selecionados. Tal procedimento teve importantes consequências, visto que, após a redefinição dos eixos e respectivas palavras usadas para a busca, foi preciso voltar à etapa inicial, realizar nova coleta no banco da Capes, confirmar e excluir trabalhos selecionados na primeira etapa do processo, bem como agregar novas teses e dissertações. Decidiu-se não se classificar os trabalhos pelos níveis, etapas e modalidades de ensino sobre os quais versam, mas por eixos temáticos, o que 
considerou a incidência, o alcance e a transversalidade das políticas sobre todos os sistemas de ensino do país.

Ainda em relação à forma de coleta, cabe informar que, entre as teses e dissertações encontradas no banco da Capes para cada grupo de palavras, foram selecionadas aquelas que estavam vinculadas a programas de pós-graduação em educação e consideradas pelos pesquisadores, com base na leitura do resumo, como estudos sobre políticas educacionais. Tendo como referência os estudos de Martins (1993), entende-se aqui política educacional como um conjunto de propostas que dão organicidade ao processo de escolarização direcionado às instituições de ensino.

Assim, foram selecionados os trabalhos que faziam referência direta ao estudo de políticas na área da educação. A título de elucidar o procedimento, a escolha dos trabalhos do eixo sobre formação de professores, por exemplo, foi direcionada àqueles cujos resumos deixavam claro ser um trabalho sobre política de formação de professores ou sobre carreira docente e não todos os trabalhos do banco que tratavam de formação de professores nos diferentes aspectos que o tema comporta.

Faz-se necessário mencionar também a existência de teses e dissertações sobre o tema das políticas educacionais em programas de pós-graduação que não são da área de educação e que, embora não tenham feito parte da pesquisa, mostram que as políticas educacionais não são objeto de preocupação exclusivo dos pesquisadores em educação e se têm constituído em objeto de estudo transversal a diversos campos do conhecimento e da ciência em nosso país.

A relevância da compreensão do campo de pesquisa sobre a temática das políticas educacionais pode ser verificada em Tello (2012), entre outros. Estudos como o de Azevedo e Aguiar (2001) apontam o campo da pesquisa sobre políticas educacionais como estando em permanente construção, evidenciando problemas e, ao mesmo tempo, potencialidades, com forte expansão a partir dos anos de 1980 (STREMEL, 2012).

A partir desses esclarecimentos e posicionamentos iniciais no que diz respeito a trabalhos que versam sobre politicas de formação de professores e carreira docente, foco deste artigo, a pesquisa gerou um banco com 204 resumos.

A seguir, são apresentadas as considerações gerais sobre a concentração das pesquisas nos programas. Espera-se contribuir com o conhecimento da temática apresentando-se as tendências da produção dos programas de pósgraduação em educação sobre as políticas de formação de professores e carreira docente, observando-se a existência, ou não, de concentração em torno de interesses específicos. 


\section{ASPECTOS DAS TENDÊNCIAS DE PESQUISA SOBRE POLÍTICAS DE FORMAÇÃO DE PROFESSORES E CARREIRA \\ DOCENTE: O QUE DIZEM OS RESUMOS DAS TESES E DISSERTAÇÕES BRASILEIRAS}

Levantamentos de pesquisa sobre formação de professores e carreira docente têm sido produzidos, dentre os quais pode se destacar o estudo recente de Brzezinski (2006, p.18) que, entre outras categorias analíticas, estabelece uma referida a pesquisas sobre Politicas e Propostas de Formação de Professores. A autora relaciona a recorrência de pesquisas sobre a temática à intensificação de ações governamentais no âmbito da redefinição de políticas educacionais e de reformas em todos os níveis de ensino, atinentes ao movimento internacional deflagrado nas últimas décadas do século XX.

$\mathrm{Na}$ mesma esteira, estudo de André (2010) analisa a constituição do campo de formação de professores no Brasil e deflagra o crescimento dos estudos sobre essa temática. No que tange à carreira docente, os estudos de Gatti, Barreto e André (2011) enfatizam a relevância de se atentar a esse debate. Contudo, levantamentos sobre pesquisas com foco específico em políticas de formação de professores e carreira docente não foram localizados, o que referenda a pertinência de estudo como o aqui proposto.

Nesse sentido, apresentamos a seguir os resultados da pesquisa que indicam peculiaridades da produção discente em programas de pós-graduação brasileiros que abordaram as políticas educativas sobre a formação e carreira docentes.

No que diz respeito ao ano de defesa, os dados levantados podem ser verificados na Tabela 1 , a seguir.

Tabela 1: Número de trabalhos sobre políticas de formação de professores e carreira docente por ano de defesa (Brasil, 2000-2010)

\begin{tabular}{|c|c|c|}
\hline Ano & Número de citações & Frequência \\
\hline $\mathbf{2 0 0 0}$ & 3 & $1,5 \%$ \\
\hline $\mathbf{2 0 0 1}$ & 9 & $4,4 \%$ \\
\hline $\mathbf{2 0 0 2}$ & 15 & $7,4 \%$ \\
\hline $\mathbf{2 0 0 3}$ & 13 & $6,4 \%$ \\
\hline $\mathbf{2 0 0 4}$ & 16 & $7,8 \%$ \\
\hline $\mathbf{2 0 0 5}$ & 20 & $9,8 \%$ \\
\hline $\mathbf{2 0 0 6}$ & 13 & $6,4 \%$ \\
\hline $\mathbf{2 0 0 7}$ & 24 & $11,8 \%$ \\
\hline
\end{tabular}


Tabela 1: Número de trabalhos sobre políticas de formação de professores e carreira docente por ano de defesa (Brasil, 2000-2010)

\begin{tabular}{|c|c|c|}
\hline Ano & Número de citações & Frequência \\
\hline $\mathbf{2 0 0 8}$ & 36 & $17,6 \%$ \\
\hline $\mathbf{2 0 0 9}$ & 29 & $14,2 \%$ \\
\hline $\mathbf{2 0 1 0}$ & 26 & $12,7 \%$ \\
\hline Total & $\mathbf{2 0 4}$ & $100 \%$ \\
\hline
\end{tabular}

Fonte: Banco de dados da pesquisa.

Com os dados da Tabela 1, nota-se crescimento expressivo do número de trabalhos no período considerado. Para melhor visualização desse aumento progressivo, ao agruparmos a produção em triênios, temos 27 trabalhos defendidos entre 2000 e 2002; 49 trabalhos entre os anos de 2003 a 2005; 73 entre os anos de 2006 a 2008 e, finalmente, 55 trabalhos considerando-se os anos de 2009 e 2010. Se, por um lado, tal crescimento pode ser compreendido pelo aumento do número de programas de pós-graduação em educação no país, é importante considerar também o debate atual sobre a necessidade de melhoria da qualidade na educação, no qual o professor é visto como peça-chave desse processo. Gatti, Barreto e André (2011), ao se referirem às políticas de formação de professores na atualidade, destacam esforço do Ministério da Educação (MEC) por constituir política nacional orientada para a instituição de um Sistema Nacional de Educação, com vistas a responder a demandas por formação inicial e continuada do magistério. Esse esforço, de acordo com a leitura dos resumos selecionados, foi o principal foco das pesquisas no período 2000-2010, como se esclarece a seguir.

A formação de professores mereceu atenção majoritária dos pesquisadores: do total de 204 trabalhos, apenas 34 se detiveram sobre a questão do trabalho e condição docente, os quais abordaram os seguintes tópicos: constituição da identidade docente, planos de carreira (de formulação obrigatória pelos estados, municípios e Distrito Federal, a partir da Emenda Constitucional $n^{\circ}$ 14/96 (BRASIL, 1996b), papel dos sindicatos na carreira, trabalho docente e novas tecnologias, o impacto e efeitos da reorganização do ensino sobre o trabalho docente, evasão da carreira e representações da população sobre a carreira do magistério. Por sua vez, dos 170 trabalhos que trataram da formação docente (inicial e continuada), 61 analisaram a formulação e a implantação das políticas, 40 se detiveram na etapa de formulação das políticas e 69 observaram a implantação das ações, sem maiores aprofundamentos sobre a análise de sua gênese. Desse total, apenas 17 trabalhos analisaram políticas educacionais em período anterior 
às reformas educacionais que se iniciaram, sobretudo, na década de 90 do século XX. Assim, em relação à formação docente, percebe-se a forte influência que a legislação do período exerceu sobre a produção acadêmica em pauta (20002010) para a configuração do campo, tendo como marco principal a publicação da Lei n 9.394/96 - LDB/96 (BRASIL, 1996a). Dentre as regulamentações que mereceram destaque no período pelos pesquisadores (além da própria LDB/96 (Idem), tem-se a Resolução CNE/CP no 01, de 15 de maio de 2006, que institui as diretrizes curriculares para o curso de Pedagogia (BRASIL, 2006) e o Decreto $\mathrm{n}^{\circ}$ 6.755/2009, que institui a Política Nacional de Formação de Professores (BRASIL, 2009). Regulamentações que incluem conteúdos curriculares na educação básica e que se relacionam com a formação continuada de professores também foram alvo das pesquisas, tais como a Lei $\mathrm{n}^{\circ} 11.161 / 2005$ (BRASIL, 2005), que torna obrigatório o ensino de espanhol nas escolas de educação básica e a Lei no 10.639/03 (BRASIL, 2003), que trata da obrigatoriedade de incluir no currículo oficial da Rede de Ensino a temática "História e Cultura Afro-Brasileira".

É importante destacar que os resumos analisados não evidenciaram. em seu conjunto, que os professores ocuparam lugar de protagonismo na formulação das políticas voltadas para a carreira e a formação docentes, tendo-lhes sido reservado o papel de executores das ações impostas pelos órgãos oficiais, como o Ministério da Educação e as secretarias de educação, em parceria com as instituições de ensino superior.

$\mathrm{Na}$ sequência, a fim de elucidar aspectos das formas como tais pesquisas têm sido produzidas, apresentam-se na Tabela 2 dados referentes às instituições que concentram o maior número de trabalhos sobre a temática das políticas de formação de professores e carreira docente no Brasil.

Tabela 2: Trabalhos sobre Políticas de formação de professores e carreira docente por Instituição (Brasil, 2000 2010).

\begin{tabular}{|c|c|c|}
\hline Instituição & Número de citações & Frequência \\
\hline UNICAMP & 29 & $14,2 \%$ \\
\hline UFRGS & 22 & $10,7 \%$ \\
\hline UERJ & 14 & $6,9 \%$ \\
\hline UNIMEP & 14 & $6,9 \%$ \\
\hline UFPR & 13 & $6,4 \%$ \\
\hline PUCRJ & 12 & $5,9 \%$ \\
\hline UFMG & 12 & $5,9 \%$ \\
\hline UFRJ & 12 & $5,9 \%$ \\
\hline UFF & 11 & $5,4 \%$ \\
\hline
\end{tabular}


Tabela 2: Trabalhos sobre Políticas de formação de professores e carreira docente por Instituição (Brasil, 2000 2010).

\begin{tabular}{|c|c|c|}
\hline Instituição & Número de citações & Frequência \\
\hline UFES & 11 & $5,4 \%$ \\
\hline UFRN & 11 & $5,4 \%$ \\
\hline FEUSP & 10 & $4,9 \%$ \\
\hline UFG & 10 & $4,9 \%$ \\
\hline UNISINOS & 7 & $3,4 \%$ \\
\hline UNESP/Mar & 6 & $2,9 \%$ \\
\hline UFU & 5 & $2,4 \%$ \\
\hline UFSCar & 4 & $2 \%$ \\
\hline PUCRS & 1 & $0,5 \%$ \\
\hline Total: $\mathbf{1 8}$ & $\mathbf{2 0 4}$ & $\mathbf{1 0 0 \%}$ \\
\hline
\end{tabular}

Fonte: Banco de dados da pesquisa.

Conforme disposto na Tabela 2, a UNICAMP se destaca como a instituição com maior número de trabalhos defendidos no período analisado. Cabe apontar a concentração dessa produção na região sudeste do país. Se considerarmos o total de instituições com ao menos dez trabalhos defendidos sobre a temática, temos 13 instituições em tais condições, sendo nove da região sudeste, concentrando $61,3 \%$ do total de trabalhos produzidos no período tratado, o que pode ser explicado pela concentração de programas de pós-graduação em educação nesta região (SANTOS; AZEVEDO, 2009).

Ao considerarmos o nível do curso em que os trabalhos foram realizados (Tabela 3), verifica-se, como era de se esperar, maior quantidade de dissertações de mestrado (64,2\%), do que teses de doutorado (35,8\%), uma vez que é maior o número de programas e de discentes de mestrado que de doutorado no país (MACEDO; SOUSA, 2010).

Tabela 3: Trabalhos sobre Políticas de formação de professores e carreira docente por Nível da pesquisa - Mestrado (M) e Doutorado (D) - (Brasil, 2000-2010).

\begin{tabular}{|c|c|c|}
\hline Nível & Número de citações & Frequência \\
\hline M & 131 & $64,2 \%$ \\
\hline D & 73 & $35,8 \%$ \\
\hline Total & 204 & $100 \%$ \\
\hline
\end{tabular}

Fonte: Banco de dados da pesquisa. 
Para uma melhor compreensão da constituição do campo educacional, verificamos quais eram as linhas de pesquisa com produção relacionada à temática em questão e a distribuição dos trabalhos em tais linhas, como um possível indicador de organicidade da produção analisada, uma vez que as linhas de pesquisa são elemento estruturador dos programas de pós-graduação em educação (MACEDO; SOUSA, 2010).

Os dados referentes à produção discente por linhas de pesquisa foram organizados na tabela a seguir:

Tabela 4: Número de trabalhos sobre políticas de formação de professores e carreira docente por linha de pesquisa e instituição (Brasil, 2000-2010).

\begin{tabular}{|c|c|c|}
\hline Linha de pesquisa & IES & N. de citações \\
\hline $\begin{array}{l}\text { Políticas de formação, políticas e } \\
\text { gestão da educação }\end{array}$ & UFRGS & 20 \\
\hline Cotidiano e cultura escolar & UERJ & 10 \\
\hline $\begin{array}{l}\text { Planejamento educacional, } \\
\text { políticas e gestão educacional }\end{array}$ & Unicamp & 9 \\
\hline Política e gestão da educação & Unimep & 9 \\
\hline Políticas públicas de educação & UFMG & 8 \\
\hline Política e práxis da educação & UFRN & 7 \\
\hline $\begin{array}{l}\text { Cultura, currículo e formação de } \\
\text { educadores }\end{array}$ & UFES & 6 \\
\hline Currículo e linguagem & UFRJ & 6 \\
\hline $\begin{array}{l}\text { Educação, relações sociais e } \\
\text { construção democrática }\end{array}$ & PUC RJ & 6 \\
\hline $\begin{array}{l}\text { Formação de professores: } \\
\text { tendências e dilemas }\end{array}$ & PUC RJ & 6 \\
\hline $\begin{array}{c}\text { Mudanças no mundo do trabalho } \\
\text { e educação }\end{array}$ & UFPR & 6 \\
\hline Educação, história e políticas & Unisinos & 5 \\
\hline Filosofia e educação & Unicamp & 5 \\
\hline $\begin{array}{l}\text { Formação e profissionalização } \\
\text { docente }\end{array}$ & UFG & 5 \\
\hline $\begin{array}{c}\text { Didática, teorias de ensino e } \\
\text { práticas escolares }\end{array}$ & FEUSP & 4 \\
\hline $\begin{array}{l}\text { Filosofia e história da educação } \\
\text { no Brasil }\end{array}$ & Unesp/Mar & 4 \\
\hline $\begin{array}{c}\text { Políticas e instituições } \\
\text { educacionais }\end{array}$ & UFRJ & 4 \\
\hline $\begin{array}{l}\text { Espaços educativos, produção e } \\
\text { apropriação de conhecimentos }\end{array}$ & UFMG & 3 \\
\hline Estado e política educacional & UFG & 3 \\
\hline
\end{tabular}


Tabela 4: Número de trabalhos sobre políticas de formação de professores e carreira docente por linha de pesquisa e instituição (Brasil, 2000-2010).

\begin{tabular}{|c|c|c|}
\hline Linha de pesquisa & IES & N. de citações \\
\hline $\begin{array}{c}\text { Formação de profissionais da } \\
\text { educação }\end{array}$ & UFF & 3 \\
\hline Políticas e gestão da educação & UFPR & 3 \\
\hline Políticas públicas e educação & Unicamp & 3 \\
\hline $\begin{array}{l}\text { Desenvolvimento humano, } \\
\text { psicologia e educação }\end{array}$ & Unicamp & 2 \\
\hline $\begin{array}{l}\text { Diversidade e práticas } \\
\text { educacionais inclusivas }\end{array}$ & UFES & 2 \\
\hline Educação e trabalho & Unicamp & 2 \\
\hline Ensino e formação do professor & Unicamp & 2 \\
\hline $\begin{array}{l}\text { Filosofia, educação, história e } \\
\text { sociedade }\end{array}$ & Unicamp & 2 \\
\hline $\begin{array}{l}\text { Filosofia: o conhecimento e a } \\
\text { educação }\end{array}$ & Unimep & 2 \\
\hline $\begin{array}{l}\text { Formação do professor, currículo } \\
\text { e ensino superior }\end{array}$ & Unicamp & 2 \\
\hline $\begin{array}{l}\text { Formação e práxis político- } \\
\text { pedagógica do professor }\end{array}$ & UFES & 2 \\
\hline Política e gestão da educação & UFPR & 2 \\
\hline $\begin{array}{c}\text { Política educacional, } \\
\text { administração de sistemas } \\
\text { educativos e unidades escolares }\end{array}$ & Unesp/Mar & 2 \\
\hline Políticas e gestão em educação & UFU & 2 \\
\hline $\begin{array}{l}\text { Avaliação de políticas e } \\
\text { financiamento da educação }\end{array}$ & UFF & 1 \\
\hline $\begin{array}{l}\text { Conhecimento, autonomia e } \\
\text { participação }\end{array}$ & UERJ & 1 \\
\hline $\begin{array}{l}\text { Conhecimento, subjetividade e } \\
\text { práticas educacionais }\end{array}$ & UFRGS & 1 \\
\hline $\begin{array}{l}\text { Cotidianos, redes educativas e } \\
\text { processos culturais }\end{array}$ & UERJ & 1 \\
\hline Cultura e história da educação & UFRN & 1 \\
\hline $\begin{array}{l}\text { Cultura e processos } \\
\text { educacionais }\end{array}$ & UFG & 1 \\
\hline Cultura, currículo e sociedade & UFRGS & 1 \\
\hline Currículo: teorias e práticas & UFRJ & 1 \\
\hline Educação e sociedade & UFRJ & 1 \\
\hline Educação em ciências & Unimep & 1 \\
\hline $\begin{array}{l}\text { Educação escolar: instituições, } \\
\text { sujeitos e currículos }\end{array}$ & UFMG & 1 \\
\hline
\end{tabular}


Tabela 4: Número de trabalhos sobre políticas de formação de professores e carreira docente por linha de pesquisa e instituição (Brasil, 2000-2010).

\begin{tabular}{|c|c|c|}
\hline Linha de pesquisa & IES & N. de citações \\
\hline $\begin{array}{l}\text { Educação especial propostas } \\
\text { psicoeducacionais para } \\
\text { deficientes e idosos; integração } \\
\text { de deficientes e idosos }\end{array}$ & UERJ & 1 \\
\hline $\begin{array}{c}\text { Educação inclusiva e processos } \\
\text { educacionais }\end{array}$ & UERJ & 1 \\
\hline Educação matemática & UFPR & 1 \\
\hline $\begin{array}{c}\text { Educação, linguagens e formação } \\
\text { do leitor }\end{array}$ & UFRN & 1 \\
\hline Ensino de ciências & FEUSP & 1 \\
\hline $\begin{array}{l}\text { Ensino de ciências e de } \\
\text { matemática }\end{array}$ & UFSCar & 1 \\
\hline $\begin{array}{l}\text { Ensino e educação de } \\
\text { professores }\end{array}$ & PUC RS & 1 \\
\hline $\begin{array}{c}\text { Estado, políticas e gestão } \\
\text { educacional }\end{array}$ & UFSCar & 1 \\
\hline Estado, sociedade e educação & FEUSP & 1 \\
\hline $\begin{array}{l}\text { Filosofia política e processos } \\
\text { históricos em educação }\end{array}$ & UFF & 1 \\
\hline $\begin{array}{l}\text { Formação de professores, } \\
\text { currículo e práticas pedagógicas }\end{array}$ & Unisinos & 1 \\
\hline $\begin{array}{l}\text { Formação e profissionalização } \\
\text { docente }\end{array}$ & UFRN & 1 \\
\hline Gestão e políticas educacionais & UFPR & 1 \\
\hline $\begin{array}{l}\text { História da educação e } \\
\text { historiografia }\end{array}$ & FEUSP & 1 \\
\hline História e educação & Unimep & 1 \\
\hline História e filosofia da educação & UNIMEP & 1 \\
\hline $\begin{array}{l}\text { História, sociedade, cultura e } \\
\text { políticas educacionais }\end{array}$ & UFES & 1 \\
\hline $\begin{array}{l}\text { Políticas de formação de } \\
\text { profissionais da educação }\end{array}$ & UFF & 1 \\
\hline $\begin{array}{l}\text { Políticas públicas e gestão em } \\
\text { educação }\end{array}$ & UFU & 1 \\
\hline $\begin{array}{c}\text { Políticas, saberes e práticas } \\
\text { educativas }\end{array}$ & UFU & 1 \\
\hline Práticas pedagógicas e currículo & UFRN & 1 \\
\hline $\begin{array}{l}\text { Práticas pedagógicas e formação } \\
\text { do educador }\end{array}$ & Unisinos & 1 \\
\hline Saberes e práticas educativas & UFU & 1 \\
\hline Sociedade, cultura e educação & Unicamp & 1 \\
\hline
\end{tabular}


Tabela 4: Número de trabalhos sobre políticas de formação de professores e carreira docente por linha de pesquisa e instituição (Brasil, 2000-2010).

\begin{tabular}{|c|c|c|}
\hline Linha de pesquisa & IES & N. de citações \\
\hline Sociologia da educação & FEUSP & 1 \\
\hline $\begin{array}{c}\text { Subjetividade: produção de } \\
\text { subjetividades e conhecimentos } \\
\text { em suas relações com processos } \\
\text { educativos e culturais }\end{array}$ & UFF & 1 \\
\hline $\begin{array}{c}\text { Teorias e práticas pedagógicas e } \\
\text { em educação }\end{array}$ & UFSCar & 1 \\
\hline Total (linhas): 71 & & \\
\hline
\end{tabular}

Fonte: Banco de dados da pesquisa.

Os trabalhos estão distribuídos em 71 diferentes linhas de pesquisa que compõem os programas de pós-graduação de 18 instituições de ensino e pesquisa do país. Cumpre assinalar que, em nove dos resumos lidos, não foi indicada pela base de dados a linha de pesquisa à qual estes se vincularam.

Também se registra que, em um mesmo programa e instituição, notamse recorrentes mudanças nas denominações das linhas de pesquisa no período analisado, apresentando algumas delas nomes diferentes dos dados atualmente fornecidos pelos programas de pós graduação. A esse respeito, a ressalva de Borges-Andrade (2003) de que "a desativação de linhas de pesquisa e a criação de outras são procedimentos encarados com naturalidade, e explicitamente previstos na burocracia da Capes" (p.169) fundamenta um parecer de que as investigações sobre políticas para a formação e a carreira docentes se vinculam a temas aglutinadores das pesquisas em educação que guardam relação entre si, mas não se cristalizam em modelos rigidamente fixados nas instituições e programas de pós-graduação, inclusive considerando-se um longo recorte temporal de uma década de produção de conhecimento sobre o tema. Tal profusão de linhas de pesquisa cujos trabalhos têm foco em políticas públicas de formação e carreira docentes pode estar relacionada também à abrangência da temática, que incide sobre pesquisas que versam tanto sobre propostas ou ações de governo, como sobre sua implantação e efeitos nas escolas e redes de ensino.

Conforme a Tabela 4, é possível verificar que a linha de pesquisa Políticas de formação, políticas e gestão da educação da Universidade Federal do Rio Grande do Sul (UFRGS) é a que concentra maior número de estudos sobre a temática - 20 trabalhos, de um total de 22 defendidos na instituição no período, mostrando certa organicidade no programa de pós-graduação da instituição. Da mesma 
forma, na Universidade Estadual do Rio de Janeiro (UERJ), a linha de pesquisa Cotidiano e cultura escolar concentra dez dos 14 trabalhos defendidos na instituição.

Em contrapartida, na Universidade Estadual de Campinas (Unicamp), as 29 pesquisas realizadas sobre o tema no período estão dispersas em nove diferentes linhas de pesquisa, a saber:

- Planejamento educacional, políticas e gestão educacional, com nove estudos (indicando certa concentração).

- Filosofia e educação, com cinco.

- Políticas públicas e educação, com três.

- Educação e trabalho; Ensino e formação do professor; Filosofia, educação, historia e sociedade; Formação do professor, currículo e ensino superior; Desenvolvimento bumano, psicologia e educação, cada qual com dois estudos.

- Sociedade, cultura e educação, com um trabalho.

- Um resumo sem informação sobre a linha de pesquisa a que se vincula.

Os resultados identificados quanto à produção vinculada a essas duas instituições - UFRGS e Unicamp - merecem olhar mais atento quanto à organicidade entre os estudos e as linhas de pesquisa. Enquanto na UFRGS foram produzidos 20 trabalhos em uma mesma linha de pesquisa, na Unicamp o foram 29 em 9 linhas, proporcionalmente, pouco mais de três trabalhos para cada linha de pesquisa. Considerando-se o pensamento de Bourdieu (2003), no caso da UFRGS, a concentração de trabalhos em uma mesma linha remete a se pensar no fortalecimento de uma tradição investigativa em torno de uma autoridade científica definida, em detrimento de certa pulverização de interesses nos temas de investigação, como se mostra nos trabalhos encontrados na Unicamp.

Voltando-se à produção das demais instituições e linhas de pesquisa, destaca-se a Universidade Metodista de Piracicaba (Unimep), com nove das 14 pesquisas defendidas na instituição, concentradas na linha de pesquisa Política e gestão da educação; a Universidade Federal do Rio Grande do Norte (UFRN), com sete dos 11 trabalhos na linha Política e práxis da educaşão; e a Universidade Federal de Minas Gerais (UFMG) com oito dos 12 trabalhos concentrados na linha Políticas públicas de educação, confirmando uma tendência maior de concentração dos estudos em linhas de pesquisa específicas do que de dispersão.

Nesse ínterim, embora todos os trabalhos selecionados na pesquisa remetam à análise de políticas de formação de professores e carreira docente, nem todos foram desenvolvidos em linhas de pesquisa que aludam às políticas públicas em seus nomes, como se pode observar na lista apresentada na Tabela 4. Um exemplo dessa situação é a linha com o segundo maior número de citações sobre o tema, que se intitula Cotidiano e cultura escolar. Esse dado pode ser lido como 
evidência de que o campo de estudos das políticas de formação de professores e carreira docente ultrapassa limites e restrições quanto a nomenclaturas formais e se caracteriza pela diversidade, tanto de métodos quanto de objetos de pesquisa, tal qual observado também por André (2010) sobre as especificidades dos estudos sobre a formação de professores em si.

Outro conjunto de dados levantado, disposto na Tabela 5, diz respeito aos orientadores dos trabalhos encontrados. Para fins de verificação de concentração de pesquisas e possível acúmulo de conhecimento, bem como da atenção que o tema vem tomando junto aos estudiosos das questões educacionais, foram destacados os pesquisadores que concentraram até duas orientações no período considerado.

Tabela 5: Principais orientadores, por Instituição, dos trabalhos sobre Políticas de formação de professores e carreira docente (Brasil, 2000 2010).

\begin{tabular}{|c|c|c|}
\hline Orientador & Instituição & Orientações \\
\hline Carmen Lúcia Bezerra Machado & UFRGS & 4 \\
\hline Edil Vasconcellos de Paiva & UERJ & 4 \\
\hline Janete Magalhães Carvalho & UFES & 4 \\
\hline Jose Luís Sanfelice & Unicamp & 4 \\
\hline Luiz Carlos de Freitas & Unicamp & 4 \\
\hline Sonia Giubilei & Unicamp & 4 \\
\hline Alda Maria D. Araújo Castro & UFRN & 3 \\
\hline Dalila Andrade Oliveira & UFMG & 3 \\
\hline Elizabeth Diefenthaeler Krahe & UFRGS & 3 \\
\hline Hermengarda Alves Ludke & PUC/RIO & 3 \\
\hline Lucíola Licínio C. Paixão Santos & UFMG & 3 \\
\hline Maria Beatriz Moreira Luce & UFRGS & 3 \\
\hline Maria de Fátima Costa de Paula & UFF & 3 \\
\hline Maria Estela Dal Pai Franco & UFRGS & 3 \\
\hline Monica Ribeiro da Silva & UFPR & 3 \\
\hline Raquel Pereira Chainho Gandini & Unimep & 3 \\
\hline Regina Helena Silva Simões & UFES & 3 \\
\hline Rose Meri Trojan & UFPR & 3 \\
\hline Waldeck Carneiro da Silva & UFF & 3 \\
\hline Walderês Nunes Loureiro & UFG & 3 \\
\hline Alice Ribeiro Casimiro Lopes & UERJ & 2 \\
\hline
\end{tabular}


Tabela 5: Principais orientadores, por Instituição, dos trabalhos sobre Políticas de formação de professores e carreira docente (Brasil, 2000 2010).

\begin{tabular}{|c|c|c|}
\hline Orientador & Instituição & Orientações \\
\hline Antônio Cabral Neto & UFRN & 2 \\
\hline Belmira Amélia B. O. Bueno & FEUSP & 2 \\
\hline Berenice Corsetti & Unisinos & 2 \\
\hline Charles Richard Lyndaker & Unicamp & 2 \\
\hline Claudia Barcelos de Moura Abreu & UFPR & 2 \\
\hline Claudia Barcelos de Moura Abreu & UFPR & 2 \\
\hline Corinta Maria Grisolia Geraldi & Unicamp & 2 \\
\hline Elie George G. Ghanem Junior & FEUSP & 2 \\
\hline Eloisa de Mattos Hofling & Unicamp & 2 \\
\hline Flávia Obino Corrêa Werle & Unisinos & 2 \\
\hline Jose Carmello Braz de Carvalho & PUC/RIO & 2 \\
\hline Jose Roberto Rus Perez & Unicamp & 2 \\
\hline Magna França & UFRN & 2 \\
\hline Marcelo Soares Pereira da Silva & UFU & 2 \\
\hline Márcia Serra Ferreira & UFRJ & 2 \\
\hline Marcos Corrêa da Silva Loureiro & UFG & 2 \\
\hline Mari Margarete S. Forster & Unisinos & 2 \\
\hline Mônica Pereira dos Santos & UFRJ & 2 \\
\hline Raquel Goulart Barreto & UFRJ & 2 \\
\hline Sueli Mazzilli & Unimep & 2 \\
\hline Valdemar Sguissardi & Unimep & 2 \\
\hline Total & & 108 \\
\hline
\end{tabular}

Fonte: Banco de dados da pesquisa.

$\mathrm{Na}$ tabela 5 é possível verificar que os orientadores com maior número de trabalhos sob sua supervisão (quatro) concentram-se na UFRGS, UERJ, UFES e Unicamp, sendo seis orientadores nessa situação, três deles na Unicamp. Depois, verifica-se um conjunto de 14 pesquisadores que possuem três orientações no período analisado. Com duas orientações temos um total de 21 pesquisadores, e 97 com apenas uma orientação. Essa forte dispersão de pesquisas sobre políticas educacionais entre diferentes orientadores pode estar relacionada às diversas possibilidades de análise das políticas, seja por um enfoque mais micro, ou seja, que investigue seus efeitos nas instituições e nos sujeitos, seja por um enfoque mais macro, que investigue suas relações com o todo social. 
Tabela 6: Número de trabalhos por país estudado.

\begin{tabular}{|c|c|c|}
\hline País & Frequência & Porcentagem \\
\hline Brasil & 199 & 97,5 \\
\hline Argentina, Brasil, Chile & 1 & 0,5 \\
\hline Brasil, Argentina & 1 & 0,5 \\
\hline Brasil, Cuba & 1 & 0,5 \\
\hline Brasil, Portugal & 1 & 0,5 \\
\hline Não indicado & 1 & 0,5 \\
\hline Total & $\mathbf{2 0 4}$ & $\mathbf{1 0 0}$ \\
\hline
\end{tabular}

Fonte: Banco de dados da pesquisa.

No que se refere ao número de trabalhos por país pesquisado, percebe-se que os pesquisadores se voltaram eminentemente à realidade brasileira: do total de resumos de teses e dissertações selecionadas, 199 (97,5\%) se concentraram no Brasil, como mostra a Tabela 6. Os estudos comparativos internacionais revelam o baixíssimo investimento dos programas de pós-graduação em pesquisas sobre política educacional comparada, bem como em intercâmbios internacionais. Um maior interesse pelas políticas educacionais em âmbito internacional poderia, inclusive. auxiliar na delimitação do campo no país, dando contornos mais específicos às características próprias da política brasileira.

As Tabelas 7 e 8 apresentam dados sobre a produção distribuída por região e estados, respectivamente:

Tabela 7: Número de trabalhos por região.

\begin{tabular}{|c|c|c|}
\hline Região & Frequência & Porcentagem \\
\hline Centro-Oeste & 16 & 8 \\
\hline Norte & 9 & 4,4 \\
\hline Sul & 39 & 19 \\
\hline Sudeste & 96 & 47 \\
\hline Não se aplica & 23 & 11,3 \\
\hline Não indicado & 21 & 10,3 \\
\hline Total & 204 & 100 \\
\hline
\end{tabular}

Fonte: Banco de dados da pesquisa. 
Tabela 8: Número de trabalhos por estado estudado.

\begin{tabular}{|c|c|c|}
\hline Estado & Frequência & Porcentagem \\
\hline Acre & 2 & 1 \\
\hline Alagoas & 1 & 0,5 \\
\hline Bahia & 3 & 1,5 \\
\hline Bahia/Pernambuco & 1 & 0,5 \\
\hline Espírito Santo & 10 & 5 \\
\hline Goiás & 6 & 3 \\
\hline Maranhão & 3 & 1,5 \\
\hline Minas Gerais & 18 & 8,8 \\
\hline Mato Grosso do Sul & 2 & 1 \\
\hline Mato Grosso & 5 & 2,5 \\
\hline Pará & 5 & 2,5 \\
\hline Paraná & 15 & 7,3 \\
\hline Rio de Janeiro & 30 & 14,6 \\
\hline Rondônia & 6 & 3 \\
\hline Roraima & 1 & 0,5 \\
\hline Rio Grande do Sul & 22 & 10,7 \\
\hline Santa Catarina & 2 & 1 \\
\hline Sergipe & 3 & 1,5 \\
\hline São Paulo & 38 & 18,5 \\
\hline Tocantins & 4 & 2 \\
\hline Não se aplica & 23 & 11,1 \\
\hline Não indicado & 4 & 2 \\
\hline Total & 204 & 100 \\
\hline
\end{tabular}

Fonte: Banco de dados da pesquisa.

De acordo com as Tabelas 7 e 8, percebe-se a concentração dos trabalhos nos estados das regiões Sudeste (São Paulo, Rio de Janeiro, Minas Gerais e Espírito Santo) e Sul (Rio Grande do Sul e Paraná). Não se pode ignorar, em relação a esses dados, a alta concentração de programas de pós-graduação nessas regiões em detrimento das demais (SOUSA; BIANCHETTT, 2007). Vale destacar que essa situação revela que os investimentos do Estado nos programas de pós-graduação nas demais regiões ainda não são suficientes, evidenciando se a persistência da desigualdade na produção e distribuição do conhecimento em nosso país.

A fim de se complementar a compreensão sobre a produção acadêmica em políticas de formação e carreira docente, investigaram-se nos resumos os aportes teóricos mobilizados pelos pesquisadores. Dentre os 102 autores citados, destacamos os mencionados ao menos três vezes, em diferentes resumos: 
- Autores internacionais que têm centrado suas investigações na temática da formação e exercício do trabalho docente: Antônio Nóvoa (12); Maurice Tradif (oito); Claude Lessard (quatro); José Contreras (três); Andy Hargreaves (três); Isabel Alarcão (três).

- Autores nacionais que discutem tal temática, como Vera Candau (quatro); Paulo Freire (quatro); Selma Garrido Pimenta (quatro).

- Autores internacionais que têm centrado seus estudos na análise das políticas públicas na contemporaneidade: Stephen Ball (nove); Boaventura de Souza Santos (quatro); Richard Bowe (três).

- Autores de fundamentação teórica mais ampla: Michel de Certeau (seis), Antonio Gramsci (quatro), Pierre Bourdieu (três), Karl Marx (três), Laurence Bardin (três).

Tem-se ainda 14 autores que foram citados duas vezes, e 71 que foram mencionados apenas uma única vez, evidenciando multiplicidade de autores, não permitindo salientar uma tendência teórica dominante nos trabalhos cujos resumos foram analisados. Outro aspecto que merece destaque é o fato de, do total de 204 resumos consultados, $133(65,2 \%)$ não apresentarem aporte teórico. Essa informação pode constar dos trabalhos completos, mas, de todo modo, explicitam-se fragilidades na elaboração dos resumos.

\section{À GUISA DE CONCLUSÕES}

O levantamento das tendências das pesquisas educacionais sobre as políticas de formação de professores e carreira docente em teses e dissertações defendidas entre os anos 2000 e 2010 nos principais programas de pós-graduação do Brasil, segundo o ranking da Capes, revela alguns apontamentos que, de forma geral, permitem-nos enxergar mais de perto a problemática aqui discutida e nos provoca à formulação de questões outras, que, talvez, fomentem a organização de novos trabalhos e de novos debates sobre a temática e os dados levantados.

Uma primeira constatação é que as preocupações com as políticas referentes à carreira docente e, principalmente, aquelas voltadas para a formação de professores, vêm aumentando progressivamente nas pesquisas educacionais e que a legislação que tem regulamentado a área, principalmente pós-LDB/96 (BRASIL, 1996a), tem influenciado na configuração do campo. Essa evidência parece indicar que o interesse pelos estudos nessa área por parte dos discentes e orientadores vem crescendo significativamente na última década.

Em segundo lugar, nota-se que a maioria dos programas de pósgraduação em educação consultados, portanto, que possuem maior qualificação da Capes, está localizada nas regiões Sul e Sudeste. Diante de tal fato, mostra-se fundamental que sejam feitos estudos sobre a produção dos programas de pós- 
graduação das outras regiões do país a fim de que se obtenha uma visão ampliada dessa área do conhecimento.

Por fim, a investigação revela que as pesquisas que se debruçam sobre políticas educacionais com ênfase em políticas de formação e carreira docentes se encontram pulverizadas entre linhas de pesquisa muito distintas. Cabe questionar se essa situação não estaria prejudicando a socialização das pesquisas e, em consequência, a consolidação desta área de conhecimento no Brasil.

\section{REFERÊNCIAS}

ANDRÉ, Marli. A pesquisa sobre formação de professores: contribuições à delimitação do campo. In: DALBEN, Ângela Imaculada Loureiro de Freitas (Org.). Convergências e tensões no campo da formação e do trabalho docente. Textos selecionados do XV ENDIPE - Encontro Nacional de Didática e Prática de Ensino - UFMG. Belo Horizonte: Autêntica, 2010.

AZEVEDO, Janete M. Lins; AGUIAR, Márcia Ângela. A produção do conhecimento sobre a política educacional no Brasil: um olhar a partir da ANPED. Educação \& Sociedade, Campinas, Cedes, v. 22, n. 77, pp. 49-70, dez. 2001.

BORGES-ANDRADE, Jairo Eduardo. Em Busca do Conceito de Linha de Pesquisa. Revista de Administração Contemporânea. Curitiba, v. 7, n. 2, p.157-170, Abr./Jun. 2003. Disponível em: http://www.scielo.br/pdf/rac/v7n2/ v7n2a09.pdf. Acesso em: 03.09.2015.

BOURDIEU, Pierre. Os usos sociais da ciência: por uma sociologia clínica do campo científico. Trad. Denice Bárbara Catani. São Paulo: Editora da UNESP, 2004.

O campo científico. In: ORTIZ, Renato (org.). A Sociologia de Pierre Bourdieu. Trad. Paula Montero e Alícia Auzmendi. São Paulo: Olho d’Água, 2003. pp. 112143.

BRASIL. Decreto $\mathbf{n}^{\mathbf{0}} \mathbf{6 . 7 5 5}$, de 29 de janeiro de 2009. Institui a Política Nacional de Formação de Profissionais do Magistério da Educação Básica, disciplina a atuação da Coordenação de aperfeiçoamento de Pessoal de Nível Superior (CAPES) no fomento de programas de formação inicial e continuada, e dá outras providências. Disponível em: http://www.planalto.gov.br/ccivil_03/_ato20072010/2009/decreto/d6755.htm. Acesso em: 17/09/2015. 
Resolução CNE/CP no 01, de 15 de maio de 2006. Institui Diretrizes Curriculares Nacionais para o Curso de Pedagogia, licenciatura. Disponível em: http://portal.mec.gov.br/cne/arquivos/pdf/rcp01_06.pdf. Acesso em: 18/09/2015.

Lei $\mathbf{n}^{\mathbf{0}}$ 11.161, de 5 de agosto de 2005. Dispõe sobre o ensino de língua espanhola. Disponível em: http://www.planalto.gov.br/ccivil_03/_Ato20042006/2005/Lei/L11161.htm. Acesso em: 18/09/2015.

Lei $\mathbf{n}^{\mathbf{0}} \mathbf{1 0 . 6 3 9}$, de 09 de janeiro de 2003. Altera a Lei no 9.394, de 20 de dezembro de 1996, que estabelece as diretrizes e bases da educação nacional, para incluir no currículo oficial da Rede de Ensino a obrigatoriedade da temática "História e Cultura Afro-Brasileira", e dá outras providências. Disponível em: http:/ /www.planalto.gov.br/ccivil_03/leis/2003/L10.639.htm. Acesso em: 18/09/2015.

Lei de Diretrizes e Bases da Educação Nacional. Lei no 9.394, de 20 de dezembro de 1996. Disponível em: < http://portal.mec.gov.br/arquivos/pdf/ ldb.pdf $>$. Acesso em 10/05/2015, 1996a.

. Emenda Constitucional n $\mathbf{1}^{\mathbf{1 4}}$, de 12 de setembro de 1996. Disponível

em: <http://www.planalto.gov.br/ccivil_03/constituicao/Emendas/Emc/ emc14.htm>. Acesso em 14/03/2015, 1996 b.

BRZEZINSKI, Iria (coord.). Formação de Profissionais da Educação (19972002). Brasília: MEC/ INEP, 2006.

GATTI, Bernardete Angelina; BARRETO, Elba Siqueira de Sá; ANDRÉ, Marli Eliza Dalmazo Afonso. Políticas docentes no Brasil: um estado da arte. Brasília: UNESCO, 2011.

MACEDO, Elizabeth; SOUSA, Clarilza Prado. A pesquisa em educação no Brasil. Revista Brasileira de Educação, Rio de Janeiro, Anped, v. 15 n. 43, pp. 166-176, jan./abr. 2010.

MAINARDES, Jefferson. Análise de políticas educacionais: breves considerações teórico metodológicas. Revista Contrapontos, Itajaí/ SC, Univali, v. 9, n.1, pp.416, jan./abr. 2009.

MARTINS, Célia. O que é política educacional. Coleção Primeiros Passos. São Paulo: Brasiliense, 1993. 
SANTOS, Ana Lúcia Felix; AZEVEDO, Janete Maria Lins. A pós-graduação no Brasil, a pesquisa em educação e os estudos sobre a política educacional: os contornos da constituição de um campo acadêmico. Revista Brasileira de Educação, Rio de Janeiro, Anped, v. 14 n. 42, pp. 534-550, set./dez. 2009.

SOUSA, Sandra Zákia; BIANCHETTI, Lucídio. Pós-graduação e pesquisa em educação no Brasil: o protagonismo da ANPEd. Revista Brasileira de Educação, Rio de Janeiro, Anped, n. 36, pp. 309-546, set./dez. 2007.

STREMEL, Silvana. Fontes para o estudo da constituição do campo da política educacional no Brasil. Jornadas latinoamericanas de estudios epistemológicos en política educativa. Anais... Buenos Aires: Universidad Nacional de Tres de Febrero, pp. 1-19, 2012.

TELLO, César Geronimo. La producción de conocimiento en política educacional: entre los nuevos modos de producción de conocimiento y el EEPE. Revista Diálogo Educacional, Curitiba, PUCPR, v.13, n. 39, pp.749-770, maio/ ago. 2013a.

- (coord. y compilador). Epistemologías de la política educativa: posicionamentos, perspectivas y enfoques. Campinas: Mercado de Letras, 2013b.

. Las epistemologías de la política educativa: vigilancia y posicionamiento epistemológico del investigador en política educativa. Práxis Educativa, Ponta Grossa/PR, UEPG, v. 7, n. 1, pp. 53-68, jan./jun. 2012.

ISABEL MELERO BELLO é doutora em Educação (USP/SP). Professora do Departamento de Educação da Unifesp, atuando na Graduação, no curso de Pedagogia e na Pós-Graduação em Educação. Membro dos Grupos de Estudo e Pesquisa em Política Educacional e Gestão Escolar (GEPPEGE) - UNIFESP e Avaliação de Políticas Educacionais - UNIFESP. E-mail: isabel.bello@unifesp.br

MARIETA GOUVÊA DE OLIVEIRA PENNA é Doutora em Educação (PUC/SP). Professora do Departamento de Educação da Unifesp, atuando na Graduação, no curso de Pedagogia e na Pós-Graduação em Educação. Membro dos Grupos de Pesquisa "Política Educacional e Gestão Escolar" (Unifesp) e "Docência em suas múltiplas dimensões” (PUC/SP).E-mail: marieta.penna@unifesp.br

MIRNA RIBEIRO LIMA DA SILVA é Mestre em Educação (UFPR). Professora no Instituto Federal de Educação, Ciência e Tecnologia Baiano (IF Baiano) 
Campus Catu, na área de Política Educacional. Membro do Grupo de Pesquisa em Educação Científica e Popularização das Ciências (GPEC). E-mail: mirna. ribeiro@ifbaiano.edu.br

Recebido em junho de 2015

Aprovado em setembro de 2015 